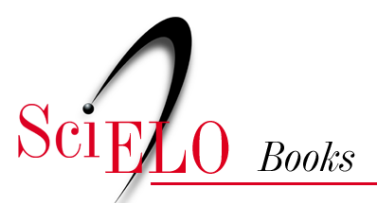

\title{
Capítulo 3 - Rasgos peculiares del quichua ecuatoriano dentro de la familia quechua
}

\author{
Luis Montaluisa Chasiquiza
}

\section{SciELO Books / SciELO Livros / SciELO Libros}

MONTALUISA CHASIQUIZA, L. Rasgos peculiares del quichua ecuatoriano dentro de la familia quechua. In: La estandarización ortográfica del quichua ecuatoriano. Consideraciones históricas, dialectológicas y sociolingüísticas [online]. Quito: Editorial Abya-Yala, 2019, pp. 141-183. ISBN: 9789978-10-496-5. https://doi.org/10.7476/9789978104965.0004.

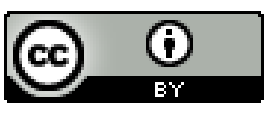

All the contents of this work, except where otherwise noted, is licensed under a Creative Commons Attribution 4.0 $\underline{\text { International license. }}$

Todo o conteúdo deste trabalho, exceto quando houver ressalva, é publicado sob a licença Creative Commons Atribição 4.0.

Todo el contenido de esta obra, excepto donde se indique lo contrario, está bajo licencia de la licencia $\underline{\text { Creative }}$ Commons Reconocimento 4.0 . 
Capítulo 3 Rasgos peculiares del quichua ecuatoriano
dentro de la familia quechua

El quichua ecuatoriano forma parte de la familia quechua presente en Colombia, Ecuador, Perú, Bolivia, Argentina y Chile. Pero, ¿con cuáles hablas quechua de esta familia, el ecuatoriano está más relacionado?, ¿cuáles son sus particularidades? Sus características pueden apreciarse mejor con el conocimiento de la evolución de los estudios dialectales realizados, principalmente, a partir del siglo XX..$^{41}$

\section{Antecedentes}

En la segunda mitad del siglo XX, Paul Rivet y Georges CréquiMontefort publicaron cuatro volúmenes (1951-1956) con la bibliografía del quechua y el aimara producida hasta entonces en los diferentes países, y sugirieron la elaboración de una gramática comparada de estas lenguas.

Posteriormente, como lo señala Cerrón-Palomino (1987, p. 94), "Rowe $[\ldots]$ abría un campo totalmente nuevo en la investigación de la lingüística histórica quechua" al concluir que el dialecto cuzqueño no era el más arcaico del quechua, ya que había experimentado más cambios que el ayacuchano. Esta visión revolucionó el pensamiento tradicional.

41 Un compendio de los intentos previos de clasificación dialectal desde la época Colonial hasta los trabajos relacionados con este tema realizados por Parker y Torero puede verse en Cerrón-Palomino (1987, 2003). 
Por su parte, Ferrario ( $c f$. Cerrón-Palomino, 1987, p. 94), basándose en indicios históricos y algunas simples inferencias lógicas, sostiene que no todas las variedades modernas están en "absoluta paridad glotológica" respecto de un protoidioma. Él observaba que las investigaciones lingüísticas de las hablas contemporáneas debían considerar como un lineamiento básico la reconstrucción de un "protorunasimi”.

A su criterio, de este "protoidioma" se habrían derivado dos ramas: el "inca clásico", del cual a su vez —en una segunda derivaciónhabrían surgido el ecuatoriano y el argentino, entre otros; y el "Chinchaisuyo”, que estaría integrado por diferentes dialectos (ayacucho, junín, huánuco, etc.) y a los cuales Ferrario considera como "neoquechuas".

Luego vino la etapa comparativa de los dialectos que comprendían el quechua con los trabajos de dos lingüistas: el norteamericano Parker (1963/2013) y el peruano Torero (1964/2003). Estos autores, además de investigar las diferencias dialectales contemporáneas de la familia idiomática mediante trabajo de campo, realizaron estudios de lingüística histórica. Así surgió el interés por estudiar las características de los distintos dialectos con la finalidad de realizar una clasificación de las hablas existentes actualmente en varios países.

Tales investigadores clasificaron de manera independiente, las diversas hablas en dos grandes grupos con sus respectivas particularidades. Parker (1963/2013) las clasificó en Quechua B (QB), que comprende las hablas de la Sierra central peruana, y Quechua A (QA), integrado por las restantes. Por su parte, Torero (1964/2003) las dividió en Quechua I (QI) y Quechua II (QII), ${ }^{42}$ y al QII lo subdividió a su vez en: QIIA (que abarca las hablas de la Sierra norte peruana), QIIB (que comprende las hablas de la Selva norte peruana, las ecuatorianas y las colombianas) y QIIC (que cubre las hablas del sur peruano, Bolivia, Argentina y Chile).

42 El QI de Torero corresponde al QB de Parker, y el QII al QA de Parker. 
Posteriormente, Torero ratificó la posición del quichua ecuatoriano en el grupo QIIB en los siguientes términos:

Lingüísticamente, el complejo dialectal ecuatoriano-colombiano (que se designará aquí simplemente como ecuatoriano) es una rama del quechua IIB, cercano a los dialectos de Chachapoyas (Amazonas) y Lamas (San Martín) del nororiente peruano, y afiliable con el habla costeño central peruana descrita en 1560 por Fray Domingo de Santo Tomás y con la de Huarochirí (serranías del departamento de Lima) recogida en un amplio conjunto de textos en los primeros años del siglo XVII (véase trascripción paleográfica y versión en francés de estos textos en Taylor, 1980) (2002, p. 98).

Sin embargo, esta clasificación no está exenta de objeciones, pues existen, por ejemplo, hablas del QIIA que comparten características con el QI. Además, hay otras hablas intermedias entre las dos grandes ramas. Así, el quechua de Pacaraos tiene características del grupo que integra el QI, pero también algunas exclusivas de él, al interior de la rama, y tiene otras que son propias del QII. Esto ha dado asidero a algunas discusiones en las últimas décadas. Se ha llegado inclusive a proponer el abandono de la división QI-QII en favor de un continuum dialectal quechua. Según esto, las diferencias dialectales no se explicarían por la cronología de la expansión, sino por el grado de coherencia en la amplia comunidad hablante debido, fundamentalmente, a la distancia geográfica. Así:

For Quechua too, the initial family-tree classification has fallen increasingly into disarray as our knowledge of the geographical diversity across the family has grown over recent decades, especially with the documentation of dialects intermediate between the supposed two main branches, or others that classify well with neither (Adelaar 1977, 1987; Taylor 1984a, 1984b). As early as Landerman (1991) it was demonstrated that the two-way QI-QII split is untenable; but because he still kept faith with the tree idealization in principle, he remained unable to offer any alternative. [...] In short Heggarty (2005) calls for the traditional family tree classification of a deep two way QI-QII split to be abandoned, in favor of a more continuum-like model instead. It 


\section{4}

thus remains to set this new view of Quechua's origins in a real-world context that might explain how and why the family diverged into such a pattern, if not by Torero's sequence of migrations (Beresford-Jones y Heggarty, 2010, p. 74).

Sin embargo, esta presunción ha sido observada recientemente por Adelaar con datos actuales de la dialectología. Este autor, para argumentar la validez de la división arbórea, emplea criterios de carácter lexical, morfológico y fonológico. Señala que de ellos, el morfológico es el más importante en la distinción de las dos ramas. En defensa de la división QI-QII, al referirse a las críticas que se han realizado a esta clasificación, indica que "por contraste, ni uno de los argumentos de índole lingüística aducidos por la literatura de las últimas dos décadas en contra de la división original del quechua en dos ramas primarias se muestra resistente al escrutinio científico" (Adelaar, 2013, p. 62).

Frente a estas discusiones cabe anotar que la clasificación dialectal de una lengua, como cualquier fenómeno social, es una abstracción y una idealización. En la operación clasificatoria de las ciencias, con frecuencia, aparecen las excepciones, aun en las ciencias naturales, ${ }^{43} \mathrm{y}$ ni qué decir en las ciencias sociales como es la lingüística. Así pues, la clasificación en dos ramas solo es un instrumento analítico que permite hacer una hermenéutica de la diversidad lingüística quechua. Además, la propuesta del continuum, aunque parece útil para explicar la presencia de algunas variantes fonológicas del QI como [ča:šaq] 'llegaré', del verbo /ĉa:/ < ĉaya-> 'llegar', y que en el QII se realiza como [čayasaq $\sim$ čayašaq čayašak čayaša], igualmente variantes morfofonémicas como el continuativo $\{$-ra: $\}$ del QI, $\{$-raya- $\}$ del QII, tampoco explica satisfactoriamente la totalidad de los fenómenos lingüísticos del que-

43 Basta recordar lo que ocurrió cuando descubrieron el ornitorrinco en el siglo XVIII, a propósito de la caracterización del grupo de animales ovíparos y vivíparos. Umberto Eco, para explicar esta complejidad tituló a una aparecida obra semiótica suya, en 1997, como Kant y el ornitorrinco. 
chua. Por eso consideramos que tanto la clasificación arbórea como la del continuum no necesariamente deben ser vistas como modelos alternativos excluyentes, sino como puntos de vista diferentes y quizás hasta contradictorios.

Por otra parte, vale recordar que desde las opiniones históricas y etnohistóricas, así como del análisis filológico-lingüístico del corpus quechua extraído de los documentos de los cronistas tempranos, existe la sospecha de que en el siglo XVI existieron dos realidades lingüísticas distintas a las cuales se las ha referido con el mismo nombre de lengua general (cf. cap. 2).

Así pues, al parecer, para los primeros cronistas y quichuistas como el religioso dominico fray Domingo de Santo Tomás (1560/1995), por "lengua general" o "lengua del inga" se entendía la variedad que se hablaba en la costa centro-sureña peruana, identificada con el antiguo señorío de Chincha. Esta variedad habría desaparecido a fines del siglo XVI. Según Adelaar (2013, p. 43) y otros autores, esta lengua general estaría identificada con el QIIB, sin embargo, más tarde, a partir del Tercer Concilio Limense (1582-1583), propugnado por los jesuitas, se identificó con el nombre de lengua general a la variedad cuzqueña (actual QIIC). Como consecuencia de esta reinterpretación antojadiza tardía, desde fines del siglo XVI y principalmente del siglo XVII, al QI se lo identificó como quechua chinchaisuyo ${ }^{44}$ (cf. Huerta, 1616/1993, p. 18) sin que hubiera razón para ello; pues este, incluso geográficamente, está distante de Chincha, que está en la Costa al sur de Lima.

Esta confusión sobre la lengua general ha sido precisada, con argumentación sólida basada en el análisis lingüístico de los textos quechuas que constan en los primeros cronistas, por Cerrón-Palomino (2015b, pp. 36-37) cuando dice:

44 Huerta (1616/1993) escribe "chinchaysuyo", en tanto que Figeiredo (1700) escribe "chinchaisuyo". 
Ahora bien, esta lengua general ha sido designada también como chinchaisuya, y a ella parece referirse, sin advertirlo, el Inca Garcilaso de la Vega, cuando trata de oponerla a su "lengua general", que no es sino el quechua que será promovido más tarde por el Tercer Concilio Limense (1582-1583). No otra cosa se desprende del pasaje de su Historia general, en el que busca explicar el imaginado desencuentro comunicativo que habrían tenido el intérprete Felipillo y el inca Atahualpa en Cajamarca, y que según el autor se habría debido, entre otros factores, al hecho de que el faraute no manejaba la lengua "del Cozco" sino la de Chinchaisuyo, y lo hacía "bárbaramente", de manera que el inca se habría visto obligado a aproximar su habla al del dialecto del lenguaraz de Poechos. Sobra señalar que la oposición dialectal insinuada por el Inca resulta arbitraria, desde el momento en que está asumiendo que Atahualpa hablaba en quechua conciliar, cuando sabemos que, aparte del anacronismo implícito, todo conduce a pensar que tanto Felipillo como el último soberano inca hablaban variedades muy afines: la lengua general llamada también chinchaisuya (CerrónPalomino, 2017, p. 89).

Asimismo, otro referente para la comprensión de las características del quichua ecuatoriano son los trabajos de reconstrucción relacionados con el protoquechua. La reconstrucción de la protolengua permite la formulación de criterios para la zonificación dialectal del quichua ecuatoriano $y$, a partir de ella, es posible analizar el proceso de estandarización de la escritura quichua (como se verá en los capítulos siguientes).

Con tales antecedentes, a pesar de las divergencias resultantes de la complejidad de toda zonificación del quechua, en el presente trabajo se presenta como referencia la ubicación del quichua ecuatoriano en las clasificaciones formuladas por los investigadores que han trabajado en lingüística histórica, a partir de las propuestas iniciales de Parker (1963) y Torero (1964). Los gráficos, que algunos de tales autores han venido postulando sobre la clasificación dialectal, permiten tener una visión panorámica de las diferentes hablas que conforman la familia lingüística. 


\section{El protoquechua}

Parker y Torero, a partir de los datos de mediados del siglo XX, rastrearon la evolución de la lengua en forma retrospectiva. El objetivo de esto fue realizar la reconstrucción del protoidioma en sus niveles fonológico, morfológico y léxico. Esta tarea ha sido continuada por algunos investigadores como Cerrón-Palomino (1987, 2003), y Adelaar con Muysken (2004). En lo que sigue se pasa revista a tales reconstrucciones para luego esbozar las características del quichua ecuatoriano.

\section{Fonemas del protoquechua según Parker}

Parker reconstruyó tres vocales más un fonema de intensidad vocálica y dieciocho consonantes, tal como puede verse en la siguiente tabla:

\section{Tabla 1}

Fonemas vocálicos y consonánticos del protoquechua (Parker) ${ }^{45}$

\begin{tabular}{|l|l|l|l|}
\hline Vocales & & \\
\hline $\begin{array}{r}\text { Anterioridad } \\
\text { Aposterioridad }\end{array}$ & Anterior & Central & Posterior \\
\hline Cerradas & $\star_{\mathrm{i}}$ & & \\
\hline Abierta & & ${ }^{* a}$ & \\
\hline
\end{tabular}

45 Se conoce que Parker publicó los trabajos de fonología y morfología en inglés entre 1969 y 1970, pero en este estudio se sigue la edición realizada por el discípulo de Parker, Rodolfo Cerrón-Palomino, quien en 2013 publicó un compendio de seis trabajos de Parker realizados entre 1963 y 1971, lo que al final resultó ser un homenaje póstumo, pues el profesor Parker había fallecido en Nuevo México el 6 de noviembre de 2010. 


\begin{tabular}{|c|c|c|c|c|c|c|}
\hline \multicolumn{7}{|l|}{ Consonantes } \\
\hline $\begin{array}{l}\text { Modo } \\
\text { articulación }\end{array}$ articulación & Bilabial & Dental & Palatal & $\begin{array}{l}\text { Retrofle- } \\
\mathrm{ja}^{46}\end{array}$ & Velar & Postvelar \\
\hline Oclusivas & ${ }^{*} \mathrm{p}$ & ${ }^{*} t$ & $*^{\prime c}$ & ${ }^{*} \hat{\mathrm{c}}$ & ${ }^{\star} \mathrm{k}$ & ${ }^{*} \mathrm{q}$ \\
\hline Fricativas & & ${ }^{*} \mathrm{~s}$ & *气̌s & & ${ }^{*} \mathrm{~h}$ & \\
\hline Nasales & ${ }^{*} \mathrm{~m}$ & ${ }^{*} \mathrm{n}$ & ${ }^{*} \tilde{\mathrm{n}}$ & & & \\
\hline Laterales & & ${ }^{\star} 1$ & $\star \lambda$ & & & \\
\hline Vibrantes & & ${ }^{{ } \mathrm{r}}$ & & & & \\
\hline Espirante retrofleja & & $\star_{\check{r}}$ & & & & \\
\hline Semiconsonantes & ${ }^{*} \mathrm{~W}$ & & ${ }^{*} \mathrm{y}$ & & & \\
\hline$* /+$ intensidad $/{ }^{47}$ & & & & & & \\
\hline
\end{tabular}

Fuente: Parker, 2013, p. 71

\section{Fonemas del protoquechua según Torero}

Torero propuso seis vocales (tres cortas y tres largas) y dieciséis consonantes, según puede apreciarse en la tabla que sigue:

46 En 1963, Parker propuso la existencia de la alveolar / ф / y la palatal /č/ en el sistema protoquechua, pero en 1969 se rectificó, postulando la existencia de las palatales /č/ y /ĉ/, simple y retrofleja, respectivamente, con lo cual coincidía con la propuesta de Torero en este punto. Los fonemas / $\hat{c} / \mathrm{y} / \check{c} /$ son en verdad africados, pero se ha hecho usual en la nomenclatura quechua/quichua ubicarlos entre los oclusivos.

47 Posteriormente, Parker reformuló su interpretación en favor de la cantidad vocálica, siguiendo en esto la propuesta de Torero. 
Tabla 2

Fonemas vocálicos y consonánticos del protoquechua (Torero)

\begin{tabular}{|c|c|c|c|c|c|c|c|}
\hline \multicolumn{8}{|l|}{ Vocales } \\
\hline $\begin{array}{l}\text { Anterioridad } \\
\text {-posterioridad } \\
\text { Apertura }\end{array}$ & \multicolumn{2}{|l|}{ Anterior } & \multicolumn{3}{|c|}{ Central } & \multicolumn{2}{|c|}{ Posterior } \\
\hline Cerradas & \multicolumn{3}{|l|}{$*_{\mathrm{i},}{ }^{*} \mathrm{i}:$} & & & \multicolumn{2}{|r|}{${ }^{*} \mathrm{u},{ }^{*} \mathrm{u}:$} \\
\hline Abiertas & & & \multicolumn{3}{|c|}{${ }^{*} \mathrm{a},{ }^{*} \mathrm{a}:$} & & \\
\hline \multicolumn{8}{|l|}{ Consonantes } \\
\hline $\begin{array}{r}\begin{array}{r}\text { Punto } \\
\text { aticulación }\end{array} \\
\text { Modo } \\
\text { articulación }\end{array}$ & Bilabial & Dental & Palatal & Retrofleja & Velar & Postvelar & Glotal \\
\hline Oclusivas & ${ }^{*} \mathrm{p}$ & $*_{t}$ & $*_{\mathrm{c}}$ & ${ }^{*} \hat{\mathrm{c}}$ & ${ }^{\star} \mathrm{k}$ & ${ }^{*} \mathrm{q}$ & \\
\hline Fricativas & & ${ }^{*} \mathrm{~s}$ & $\star_{\mathrm{s}}$ & & & & ${ }^{\star} \mathrm{h}$ \\
\hline Nasales & ${ }^{*} \mathrm{~m}$ & ${ }^{*} \mathrm{n}$ & ${ }^{*} \tilde{\mathrm{n}}$ & & & & \\
\hline Laterales & & & $\star \lambda$ & & & & \\
\hline Vibrantes & & ${ }^{*} \mathrm{r}$ & & & & & \\
\hline Semiconsonantes & ${ }^{*} \mathrm{~W}$ & & ${ }^{*} \mathrm{y}$ & & & & \\
\hline
\end{tabular}

Fuente: Torero, 1964/2003

Como puede apreciarse en los cuadros vocálicos, Parker consideró, inicialmente, tres vocales cortas más un fonema de intensidad vocálica, en tanto que Torero siempre consideró tres vocales orales cortas con su correlato de tres vocales largas. Las tres vocales largas solo existen en los dialectos que conforman el QB de Parker, equivalente del QI de Torero, y están restringidas a la primera persona posesora y actora, pero también a algunos morfemas verbales compartidos por ambas ramas de la familia.

En los dialectos del quichua ecuatoriano no existen vocales largas, excepto en la Amazonía central, donde se da el alargamiento de la vocal /i/ cuando se añade el morfema locativo $\{$-pi $\}$ a una palabra que termina en /i/. Los gramáticos del siglo XIX, que elaboraron textos de la variedad 
ecuatoriana, no reportaron este fenómeno, sea porque no existía entonces o porque no le prestaron atención. En todo caso, se trata de un fenómeno puramente fonético, marginal, que se puede ver, por ejemplo, en:

[wasi: kawsani] > /wasipi kawsani/ 'vivo en casa'

Ahora bien, como se puede observar en la Tabla 1, en ambos casos estaban incluidas las semiconsonantes. La diferencia de la reconstrucción de Parker frente a la de Torero está en que el primero admite la existencia de dos laterales: una alveodental ${ }^{\star} / 1 /$ y otra palatal ${ }^{\star} / \lambda /$, en tanto que el segundo solo admite la palatal. Parker incluía, además de una vibrante ${ }^{\star} / \mathrm{r} /$, una espirante retrofleja ${ }^{\star} / \check{\mathrm{r}} /$. La /1/ era tratada por Parker como aimarismo, pero reconstruible, mientras que Torero la rechazaba. Otra diferencia era que Torero consideraba que la fricativa velar ${ }^{\star} / \mathrm{x} /$ postulada por Parker habría sido una glotal ${ }^{*} / \mathrm{h} /{ }^{48}$

En cuanto a las vocales, Torero postuló el alargamiento vocálico en tanto que Parker interpretó este fenómeno como acento de intensidad. Finalmente, Parker aceptó la propuesta de Torero y descartó la presencia de vocales largas (cf. Cerrón-Palomino, 1987).

\section{Fonemas del protequechua según Cerrón-Palomino}

Este autor, reconstruyó tres vocales y dieciséis consonante. Luego de su análisis no incluyó en su reconstrucción las vocales largas propuestas por Torero; tampoco los segmentos /řl ni /l/ propuestos por Parker. Los protofonemas ofrecidos aparecen seguidamente en los cuadros respectivos.

48 Se conoce que la diferencia entre estos dos autores en el uso de $<\mathrm{x}>\mathrm{y}<\mathrm{h}>$ era más de notación que de estructura. 


\section{1}

Tabla 3

Fonemas vocálicos y consonánticos

del protoquechua (Cerrón-Palomino)

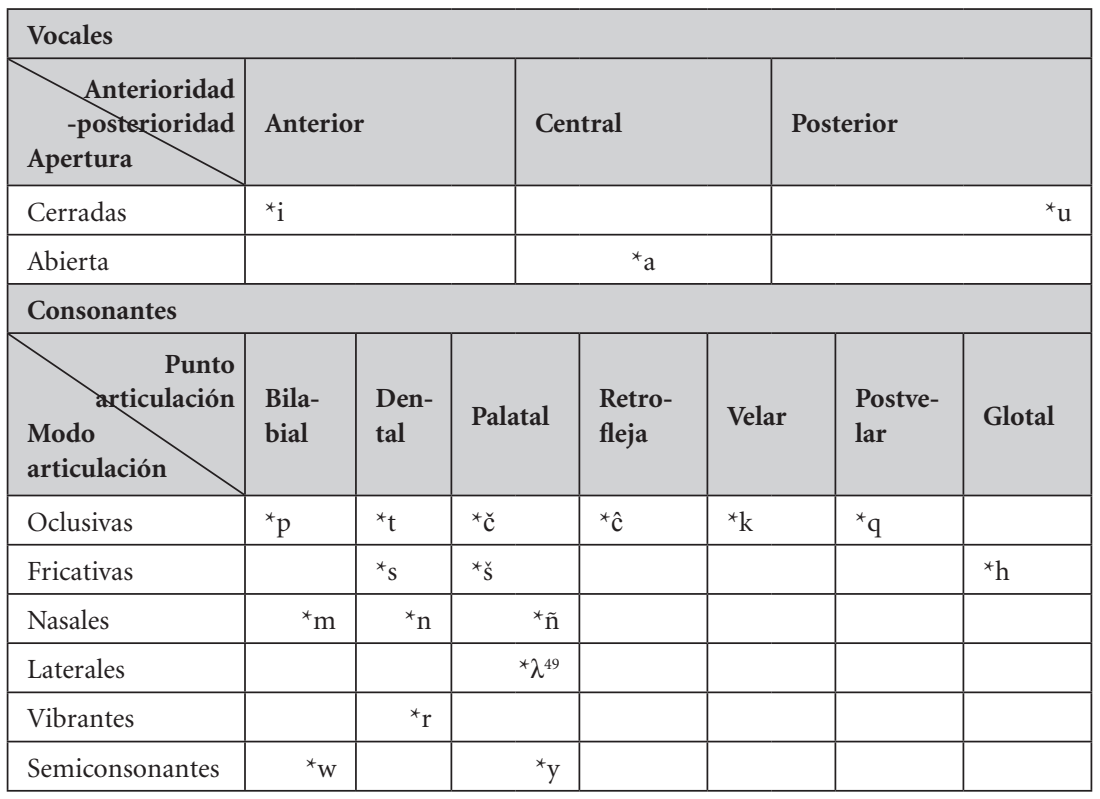

Fuente: Cerrón-Palomino, 1987, p. 128

Al comparar los elementos del sistema consonántico del quichua ecuatoriano actual, cuyo cuadro se expone más abajo, se observa que este se explica naturalmente a partir del sistema del protoquechua, dejando de lado las particularidades provenientes del sustrato, y de su propia evolución. Sin embargo, como se verá en el capítulo 5, la gran variedad del ecuatoriano, está en la realización de los fonemas, y los morfemas, es decir en el nivel de la concretización fonética. A nivel morfológico es donde existen más diferencias respecto de la protolengua, pues no

49 En el original $/ \lambda /$ se halla representado por el símbolo /Ĩ/. 
152

solamente ha habido cambios morfofonéticos, sino también una reducción cuantitativa importante de morfemas, y además de innovaciones no menos interesantes.

\section{Clasificación de los dialectos quechuas y ubicación del quichua ecuatoriano dentro de la familia lingüística}

Diversos autores han ensayado propuestas de clasificación dialectal y la ubicación del ecuatoriano al interior de lo que algunos consideran como una familia de lenguas antes que meramente grupo de dialectos perteneciente a una misma lengua.

\section{Ubicación del quichua ecuatoriano en el diagrama de Parker (1969)}

En la clasificación de 1963, Parker, ubicó al quichua ecuatoriano junto a las variedades dialectales de la Amazonía peruana, cuando señaló: "Aunque claramente derivado del dialecto del Cuzco, el de EcuadorUcayali, a menudo llamado quichua y no quechua, muestra muchas características divergentes" (1963-1972/2013, p. 39). ${ }^{50}$

Años más tarde, como se puede ver en el esquema de abajo, Parker (1969b/2013, p. 63) ubicó al dialecto ecuatoriano junto al sureño del Cuzco y de Ayacucho, y no junto al de Amazonas del Perú. ${ }^{51}$ El argumento fue que, si bien el ecuatoriano comparte varias características comunes con este último, no ha conservado el fonema palatal retroflejo /ĉ/. Por otra parte, señaló que las dos innovaciones compartidas: sonorización de oclusivas después de nasal y fusión de /k/ y /q/, integraban

50 Se presenta solo la clasificación de las hablas del QA de Parker (equivalente al QII de Torero) y no el QB (QI de Torero), porque en este se encuentra el ecuatoriano.

51 Al parecer, al referirse en 1969 al habla Amazonas, Parker no incluyó en ella las hablas del departamento amazónico de Loreto. 


\section{3}

cambios que definían un "grupo areal” y no de evolución interna de las hablas.

\section{Figura 2}

\section{Clasificación dialectal del QA}

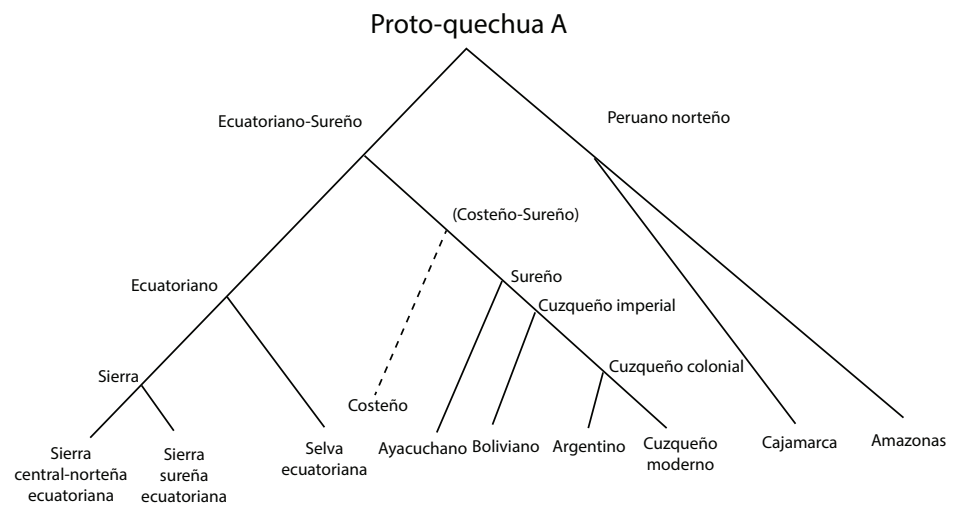

Fuente: Parker, 1963-1972/ 2013, p. 63

Actualmente, con los datos de Mercier (1983), Taylor (1979) y Landerman (1973), se puede concluir que el quichua ecuatoriano tiene más en común con las hablas de los ríos Napo, Tigre y Pastaza peruanos, del departamento de Loreto, que con el de Chachapoyas, del departamento Amazonas.

\section{Ubicación del quichua ecuatoriano en la clasificación de Torero (1974)}

Como se observa en la figura, Torero (1974/2007, p. 154) ubicó al quichua ecuatoriano junto con las hablas amazónicas del Perú y de Colombia, las cuales constituyen el grupo QIIB establecido en 1964. 


\section{4}

\section{Figura 3}

\section{Clasificación dialectal del quechua según Torero}

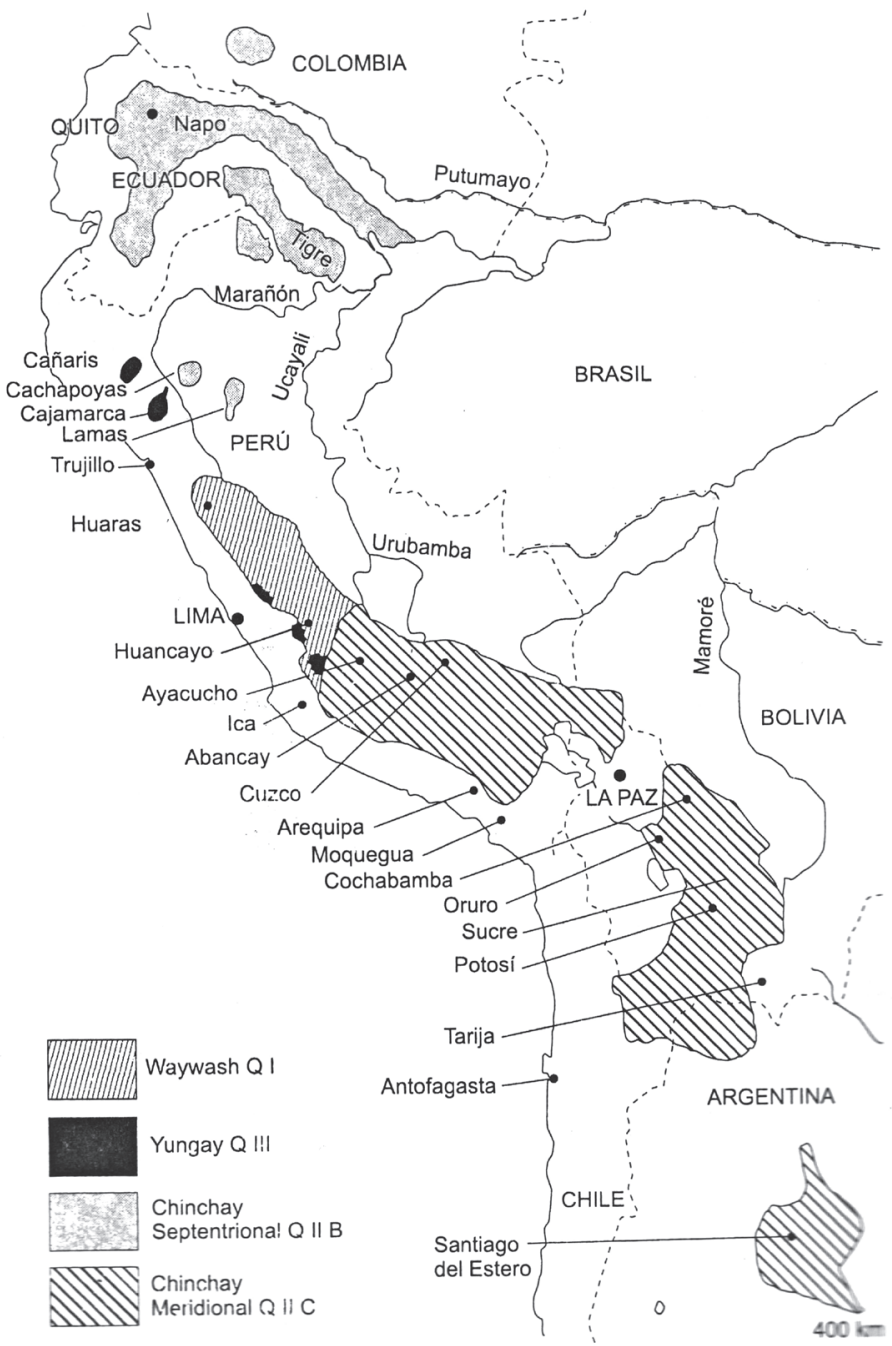

Fuente: Torero, 1974/2007, p. 154. 
155

\section{Ubicación del quichua ecuatoriano en el diagrama de Cerrón-Palomino (1987)}

En la figura siguiente, Cerrón-Palomino (1987, p. 247) sitúa al quichua ecuatoriano como parte del QIIB junto con las hablas de los departamentos peruanos de San Martín, Amazonas y Loreto, a las cuales añade las de Colombia. Sin embargo, nótese que en el quichua de las hablas de Chachapoyas, provincia del departamento de Amazonas, así como en el ecuatoriano, existe una diferencia importante. Según Taylor (2000, p. 48), en Chachapoyas existe la distinción entre /č/ y / ĉl, en tanto que en las hablas ecuatorianas este último fonema no existe.

Figura 4

Ubicación del quichua ecuatoriano al interior de la familia quechua

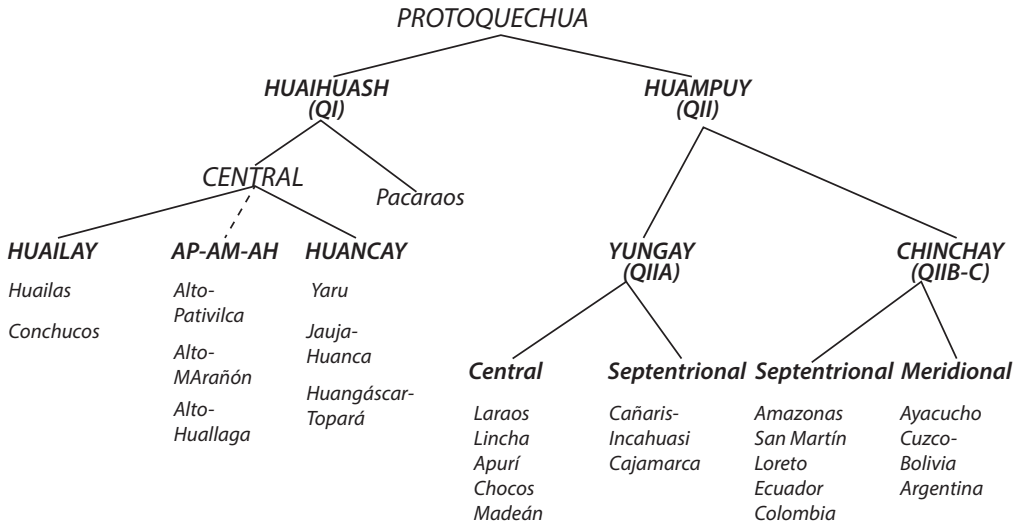

Fuente: Cerrón-Palomino, 1987, p. 247

A las hablas que integran el QIIB señaladas por los autores citados y que están relacionadas con las ecuatorianas, se tendría que agregar la del grupo denominado "santarrosino" del departamento Madre de Dios en Perú, señalada como integrante de la "napeña” por Marcos Mercier: 
156

Actualmente en su variedad NAPEÑA es el principal, y a veces único idioma de comunicación de unos 45 mil nativos de la cuenca del Napo, desde Mazán en el Perú hasta las cabeceras en el Ecuador. Hablantes del kichwa del Napo se encuentran también en comunidades de Alamas de los ríos Tigre y Pastaza, y aún en la lejana Madre de Dios, por el río Tahuamanú, a donde caucheros se llevaron un grupo de Santorrosinos (1983, p. 29). ${ }^{52}$

\section{Características del quichua ecuatoriano}

Al hablar de las características del quichua ecuatoriano se debe señalar que es imposible circunscribir las características de un dialecto al territorio de un país, pues algunas de ellas sobrepasan las fronteras nacionales, y otras, por el contrario, solo cubren una parte del territorio nacional.

Como se ha visto en los diagramas presentados, los autores que han formulado las clasificaciones del quechua desde la segunda mitad del siglo XX, señalan que las hablas que constituyen el quichua de Ecua-

52 Con "santarrosino" se refiere a los quichuas de la población de Santa Rosa, ubicada en el río Napo (Tena, Ecuador), los cuales fueron llevados por un cauchero al departamento Madre de Dios (Perú), en la Selva, a la altura del Cuzco. Luis Canelos Macochoa — de aproximadamente cuarenta años en 1984- decía sobre los padres de su generación: "Fueron traídos un centenar de ellos por el cauchero Arturo Reátegui, en 1911, y llegaron a la boca del tío Tacuatimanu un 30 de Agosto de dicho año, motivo de su denominación. Vivieron regados a través del río Tacuatimanu durante unos cuatro años, trabajando como peones para diversos caucheros y siringueros quienes abandonaron Madre de Dios alrededor de 1915 y no les pagaron el pasaje de retorno" (Pozzi-Escot, 1998, p. 298). Por otra parte, en la memoria de los hablantes de Tena está que en tiempos de sus abuelos solían viajar por el Napo hasta el río Huallaga (Perú) para proveerse de sal; cuentan que se demoraban seis meses en ese periplo, pues para los quichuas ecuatorianos de la Amazonía era más factible ir al Perú por río, que cruzar la Cordillera oriental y salir a Quito o a la Costa. Contactos como estos pudieron haber sido un factor importante para la unidad dialectal de toda esta zona. 
dor están relacionadas actualmente con las variedades quechuas de la Selva noreste peruana, que se encuentran en los departamentos de Loreto, San Martín y Amazonas, así como en Colombia. Sin embargo, cabe anotar que la variedad quechua de Amazonas tiene una diferencia importante, pues mantiene la distinción entre los fonemas /č/ y /ĉc/, de la cual carece el ecuatoriano.

La razón para que confluyan características comunes entre las hablas que constituyen el QIIB, se debe posiblemente a que en el siglo $\mathrm{XVI}^{53}$ ellas habían sido difundidas por misiones del Obispado de Quito. Además, los jesuitas atendieron gran parte de la Amazonía ecuatoriana, y también Maynas, hasta su expulsión en 1767. El padre Ortiz, al referirse al papel de los jesuitas y a los textos empleados en la evangelización de los indios del Ecuador, dice:

En Quito y en Perú se utilizaron los mismos textos gramaticales y doctrinales [...]. Cuando se hace referencia al Ecuador o al Quito de esa época, hay que tener presente que el territorio de la Real Audiencia de Quito y del Obispado de Quito se extendía bastante más que el Ecuador de hoy día. El Obispado de Quito llegaba hasta Cajamarca y Trujillo y comprendía la inmensa región de la Misión de los Maynas. Esta Misión abarcaba las cuencas de los afluentes del Marañón por parte del Perú: Huallaga, Ucayale, Panapura: colindaba con el territorio del obispado de Charcas (Bolivia) y por el oriente con el Brasil. El quichua "quiteño" se habló en todas las comarcas a donde llegaban los jesuitas con sus misiones. Por esto la Gramática o Arte del Quichua que edita en 1753 el jesuita Nieto Polo del Águila es para la Provincia de Quito y para las misiones de Maynas (2001, p. 36).

Según los estudios comparativos, las particularidades de los dialectos del quichua ecuatoriano se pueden encontrar en el campo fonético-fonológico, morfológico y léxico. A nivel sintáctico la diferencia

53 A partir del siglo XVII la zona de Chachapoyas pasó a conformar el Obispado de Trujillo, cuando éste fue organizado separándose del de Quito. 
158

entre los dialectos es menor y no solo dentro del quichua ecuatoriano, sino al interior de toda la familia lingüística. Al respecto, Parker dice: "Los textos disponibles para diversos dialectos muestran un alto grado de homogeneidad sintáctica, a excepción de lo relativo a la reestructuración que ha resultado del prestamo de preposiciones y conjunciones del castellano en ciertos dialectos" (1969c/2013, p. 77).

A continuación se presentan cinco particularidades del quichua ecuatoriano en al campo fonológico y varias en el nivel morfológico, desagregadas en la morfología nominal y en la verbal.

\section{Nivel fonológico}

El sistema fonológico fundamental del quichua ecuatoriano actual no es muy distinto de los propuestos para el protoquechua por Parker, Torero y Cerrón-Palomino que han sido señalados. A continuación se presentan los cuadros vocálico y consonántico del quichua ecuatoriano actual. En tales cuadros se tendría que incluir los fonemas provenientes de las lenguas de sustrato, de los cuales se hablará en el capítulo 7 que trata sobre la estandarización de la escritura del quichua.

Tabla 4

Cuadro de los fonemas vocálicos

y consonánticos del quichua ecuatoriano

\begin{tabular}{|l|l|l|l|}
\hline Vocales $^{54}$ & \multicolumn{2}{|l|}{} \\
\hline $\begin{array}{r}\text { Anterioridad } \\
\text { Aposterioridad }\end{array}$ & Anterior & Central & Posterior \\
\hline Cerradas & i & & \\
\hline Abierta & & a & \\
\hline
\end{tabular}

54 En Ecuador no se ha dado el problema por el número de vocales como ha ocurrido en el Cuzco, pues todos están de acuerdo en la existencia de tres vocales. La discusión se ha dado en torno a las consonantes. 
159

\begin{tabular}{|c|c|c|c|c|c|c|}
\hline \multicolumn{7}{|l|}{ Consonantes $^{55}$} \\
\hline $\begin{array}{l}\text { Modo } \\
\text { articulación }\end{array}$ & Bilabial & Dental & Palatal & $\begin{array}{l}\text { Palatal } \\
\text { retrofleja }\end{array}$ & Velar & Postvelar \\
\hline Oclusivas & $\mathrm{p}$ & $\mathrm{t}$ & $\check{\mathrm{c}}$ & & $\mathrm{k}$ & \\
\hline Fricativas & & s & š & & $\mathrm{x}$ & \\
\hline Nasales & $\mathrm{m}$ & $\mathrm{n}$ & $\tilde{\mathrm{n}}$ & & & \\
\hline Laterales & & 1 & $\lambda$ & & & \\
\hline Vibrantes & & r & & & & \\
\hline Semiconsonantes & $\mathrm{w}$ & & $y$ & & & \\
\hline
\end{tabular}

Fuente: Álvarez y Montaluisa, 2017

Las diferencias más importantes se deben a los efectos de los fenómenos de evolución que han tenido en el tiempo y en el espacio las diferentes hablas del quechua/quichua, y a la presencia de algunos sonidos provenientes de las lenguas de sustrato. Así por ejemplo, en el caso del quichua de Cañar y Azuay, pervive hasta el día de hoy un importante léxico de la lengua Cañar ( $c f$. cap. 1), en el cual existe la presencia del fonema /ž/ que se transcribe como $<\mathrm{zh}>$. En el siguiente ejemplo se puede apreciar la necesidad de incluir esta grafía para diferenciarla de la grafía del fonema $/ \lambda /$ :

\begin{tabular}{|ll|}
\hline Zhadan & 'una planta' \\
Llatan & 'desnudo, pelado' \\
\hline
\end{tabular}

55 En los dialectos de la Sierra centro y parte de la Sierra sur del Ecuador, existe un reducido número de palabras con sonidos aspirados $\left[\mathrm{p}^{\mathrm{h}}, \mathrm{t}^{\mathrm{h}}, \mathrm{ch}^{\mathrm{h}}, \mathrm{k}^{\mathrm{h}}\right]$, que podrían provenir de un superestrato de origen cuzqueño. Adicionalmente, hay la presencia de los fonos [e, o, $\varnothing, \check{z}, \mathrm{z}, \mathrm{b}, \mathrm{d}, \mathrm{g}, \mathrm{f}]$ en el léxico, provenientes de las lenguas de sustrato. Actualmente existe la presencia del fono [h] proveniente del fonema /q/ en el quichua de Tungurahua y Chimborazo, posiblemente como superestrato también del Cuzco. Por otra parte, hay que señalar que en el cuadro fonológico, siguiendo la tradición de la lingüística quechua, el fonema africado /č/ se representa en la fila de las oclusivas y no aparte, como podría ser. 
160

Inclusive se tendría un par mínimo en el quichua actual de la provincia de Cañar entre estos dos fonemas que se representan con las grafías /ll, zh/.

\begin{tabular}{|ll|}
\hline Killu & 'amarillo' \\
Kizhu & 'vagina' \\
\hline
\end{tabular}

A continuación veremos las diferencias principales del quichua ecuatoriano con relación al sistema de los otros dialectos.

La no presencia del fonema /q/

En los dialectos del quichua ecuatoriano no se da el fonema /q/, debido a que este elemento se ha velarizado $y$, consecuentemente, fusionado con $/ \mathrm{k} /$. Esta característica parece ser de larga data, pues desde los documentos del siglo XVIII, que son los primeros que se conoce del ecuatoriano, no se registra representaciones de este fonema. La no distinción de / $/$ con /q/ se da, actualmente, tanto en el Ecuador, en el ingano de Colombia como en la Amazonía peruana. Podría tratarse de un fenómeno de innovación compartida. Ejemplos:

\begin{tabular}{|llll|}
\hline Protoquechua & $\begin{array}{l}\text { Ecuatoriano- } \\
\text { ingano }\end{array}$ & $\begin{array}{l}\text { Amazonía } \\
\text { peruana }\end{array}$ & Glosa \\
/ñqa/ & $/$ ñuka/ & /nuka/ & 'yo' \\
/qam/ & $/ \mathrm{kan} /$ & $/ \mathrm{kan} /$ & 'tu' \\
/puriq/ & $/$ purik/ & $/$ purik/ & 'caminante' \\
\hline
\end{tabular}

Sonorización de las consonantes oclusivas

Las oclusivas sordas /p, t, č, k/ se sonorizan después de nasal y en algunos casos en posición intervocálica. Sin embargo, en el trabajo de campo se encontró que la sonorización no es regular ni se da por igual en el léxico de todas las zonas dialectales ( $c f$. cap. 5). Además, en algunos 
casos, las reglas de sonorización son diferentes en un contexto morfológico, a diferencia de lo que ocurre en el nivel lexical.

El fenómeno de la sonorización de las oclusivas sonoras después de nasal, lo comparten el ingano de Colombia, toda la Amazonía peruana y parte del QIIA. Inclusive habría participado de este el quechua costeño-central, según los datos proporcionados por el Lexicón de Domingo de Santo Tomás (1560/1995). Parker llega a sostener que la sonorización de las oclusivas después de nasales sería una "característica areal” (1969b/2013, p. 63), es decir, no sería una innovación compartida.

\section{La presencia restringida de aspiradas}

Existen algunos autores que han visto en el quichua ecuatoriano más relación con el cuzqueño que con el tardíamente denominado chinchaysuyano. Así, Grimm dice que "Aunque el dialecto del Chinchaysuyo se habla al norte del Cuzco, el de Quito tiene más semejanza con la lengua del Cuzco sobre todo en las formas gramaticales" (1896, p. v). Sin embargo, en el caso de la presencia de las aspiradas que es un fenómeno característico del quechua cuzqueño actual, en Ecuador, de las seis zonas dialectales en que se han dividido los dialectos del Ecuador, según los resultados de la investigación que se presentan en el capítulo 5, la única zona donde existe un limitado número de palabras con aspiración es la zona de la Sierra centro. Las provincias donde existe más presencia de aspiradas son: Cotopaxi, Tungurahua, Chimborazo y Bolívar.

Este fenómeno es reducido en relación al cuzqueño actual, no solo en cuanto al léxico, sino también a nivel posicional, pues solo se da en posición inicial de palabra. En el habla del Cuzco se da también en otras posiciones. $\mathrm{Al}$ respecto, Muysken dice:

Parker (1969) ha mostrado que la relación léxica entre los aspirados y glotalizados cusqueños [sic] y los ecuatorianos es muy confusa y asistemática. Parece ser del mismo [sic] índole que la relación entre globalización y aspiración en aymara y en el quechua cusqueño, tal como 
descrito por Stark (1975). La semejanza parece tan superficial que es más probable que se debe a influencia posterior que a una $[$ sic $]$ origen común (1977, p. 6).

Por otra parte, cabe anotar que los términos que portan aspiración en la Sierra centro del Ecuador no necesariamente coinciden con los del Cuzco. Es ilustrativo de esta asimetría el cotejo realizado por Torero (2002). Este autor, basándose en el diccionario de Stark y Muysken (1977) y Cusihuaman (1976), dice:

A) Solamente 32 glotalizadas o aspiradas cuzqueñas corresponden a aspiradas o a /ts/ (cinco casos, todos relacionados con /ch'/ cuzqueña). En cambio 43 glotalizadas y aspiradas del Cuzco —un número mayor- se presentan sin aspiración en Ecuador; esto, únicamente $42,6 \%$ de glotalizadas y aspiradas cuzqueñas hallan correspondencia en aspiradas o /ts/ ecuatorianas. Por otro lado, las hablas interandinas exhiben con aspiradas 25 raíces que solo tienen consonantes llanas en cuzqueño o en los demás dialectos peruanos. La cifra de casos en común se reduce así a $32 \%$. Se ha incluido a /ts/ inicial de palabra porque, aparte de aparecer en vocablos no evidentemente quechuas o de corresponder en tres ocurrencias a /tR/ de raíces quechuas, muestra en los cinco casos ya aludidos correspondencia con /ch'/ de Cuzco. B) Los porcentajes de ocurrencia de oclusivas aspiradas (o de fricativas) dentro de los totales con sus correlatos no aspirados son, en las raíces quechuas del ecuatoriano interandino, muy inferiores a los índices que arroja la correlación glotalizadas y aspiradas/llanas en el habla cuzqueña: orden labial 11, 7\% (Cuzco 31,4\%); dental 5,1\% (Cuzco 38,8\%); velar 12,7\% (Cuzco - velar y uvular- 46,2\%). Incluso, en el orden palatal africado, donde Cuzco ostenta la alta cifra de 59, 5\% de glotalizadas y aspiradas (haciendo las glotalizadas por sí solas el 48,9\% del total), el ecuatoriano no presenta sino la africada palatal llana, excepto en los tres casos mencionados, en los que se reconoce una sola palabra obviamente quechua: 
ch’uca ([ch"uka]) "saliva", "escupir” ${ }^{56}$. Esta raíz, que se consigna para otros sitios de Ecuador como t'uca ([t"uka]) y ty'uka ([ty"uka]), es, por lo demás significatimavente, la única que guarda correspondencia con /t"'/ cusqueña /t"uqa -/ (Torero, 2002, pp. 106-107).

La asimetría no solo se encuentra al comparar entre el Cuzco y la Sierra centro del Ecuador, sino también al interior de la misma zona ecuatoriana ( $c f$. cap. 5). La situación de la distribución de las aspiradas problematiza su inclusión en la representación escrita estandarizada.

El fenómeno de la presencia de las aspiradas en el Ecuador podría ser explicado teniendo en cuenta la presencia de mitimaes provenientes del Cuzco. El contingente invasor de Túpac Yupanqui habría estado integrado por personas hablantes de quechua y aimara que manejaban las consonantes aspiradas. En dicha ocasión se habría dado una introducción masiva del quechua sureño a los territorios de la Sierra sur y centro del Ecuador. Durante el reinado de Huaina Cápac, estos territorios ya habrían estado bajo el dominio inca y allí habría habido una mayor presencia de gente cuzqueña en la administración y vigilancia de la zona. Entonces, la presencia de aspiradas en el quichua se podría explicar como un efecto de superestrato.

A continuación, presentamos el territorio de la Sierra centro del Ecuador donde están los términos con el fenómeno de aspiración.

56 En otras zonas dialectales del Ecuador 'saliva' se realiza como [thuka, tyuka, tuka]. En el cuzqueño es thoqay (Cusihuaman, 1976, p. 153). Torero manifiesta que su fuente es Cushihuamán (1976), pero en lugar de thoqay lo trascribe como /t"uqa-/. Torero, en este texto, transcribe los sonidos oclusivos aspirados sordos con el símbolo " en lugar de poner h junto a los símbolos de estos. 
Figura 5

Zona con sonidos oclusivos aspirados

REPU⿴LICA DEL ECUADOR



Fuente: el autor 
La complejidad en la fusión de las dos africadas č $/ \hat{c}^{57}$

En el protequechua reconstruido, todos los autores señalan la presencia de dos africadas: /ĉ/ y /č/. En la variedad Junín-Huanca, correspondiente al QI (Cerrón-Palomino, 1976, p. 39) traza la distinción entre /ĉ/ y /č/. Parker (1976, pp. 45-46) apunta que en Siguas-Ancash también se mantienen las dos africadas señaladas. Igual situación se advierte en la variedad Cajamarca-Cañaris del QIIA (Quesada, 1976, p. 35; Taylor, 2000, pp. 48-59) en Chachapoyas, aunque anota que en el habla de los aculturados ya está desapareciendo /ĉ/ y que en Lamas ya ha desaparecido.

En Ecuador estos dos fonemas se han fusionado mayoritariamente en /č/ ${ }^{58}$ Por ejemplo: /ĉaki/ 'pie' y /čaki/ 'seco', han devenido en /čaki/ 'pie', y /čaki-šqa/ en /čakiška/ 'seco'.

Por otra parte, en la variedad Ancash-Huailas del QI, Parker (1976, pp. 45-46) registra en Corongo y Huaraz la distinción entre los

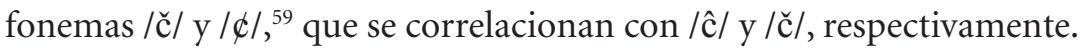

En Ecuador, la distinción entre /č/ y / \/ es más compleja debido a la intromisión del fonema /č'/ del cuzqueño. De los 175 vocablos portadores de /č'/ recopilados por Cusihuamán (1976), solo 42 palabras tienen significado en todas las zonas o al menos en alguna parte de Ecuador. Esto equivale a un $24 \%$ del total. De estas, una decena de palabras se realizan como $[\check{c} \sim \varnothing]$. El resto se realiza como [ $\check{c}]$ en todo el Ecuador. Así, en algunas hablas / $/$ / aparece como variante de /č/. Por ejemplo:

57 Como ya se dijo, en los cuadros fonológicos se ha hecho tradición en la lingüística andina el considerar a las africadas como parte de las oclusivas.

58 Aunque /č/ y / $/$ se han fusionado en el Ecuador en /č/, existen palabras quichuas que en cinco de las seis zonas dialectales se pronuncian con [ $\not$ ]. Por ejemplo: [pacak] 'cien', aunque en el protoquechua de Parker aparezca como "paĉak" y en los diccionarios del siglo XVI se escriba "pachak".

59 En el texto original de Parker (1976) el fonema / $\not /$ se representa con el símbolo /c/ (cf. Cerrón Palomino, 1987, para mayor información sobre la situación actual






\begin{tabular}{|c|c|c|c|c|}
\hline Variaciones & Unificado & Lugares (Ecu.) & Cuzco & Glosa \\
\hline $\begin{array}{l}\text { [čarki] } \\
{[\text { carki] }}\end{array}$ & /čarki/ & $\begin{array}{l}\text { Sierra centro y sur } \\
\text { Sierra norte }\end{array}$ & /č’arki/ & 'cecina, flaco' \\
\hline $\begin{array}{l}\text { [ačira] } \\
\text { [açira] }\end{array}$ & /ačira/ & $\begin{array}{l}\text { Sierra sur } \\
\text { Sierra norte y centro }\end{array}$ & /ačira/ & 'raíz comestible' \\
\hline $\begin{array}{l}\text { [čawar] } \\
\text { [ çawar] }\end{array}$ & /čawar/ & $\begin{array}{l}\text { Sierra centro y sur } \\
\text { Sierra norte }\end{array}$ & /č’awar/ & 'penco' \\
\hline $\begin{array}{l}{[\text { čini }]} \\
{[\text { ćini }]}\end{array}$ & /čini/ & $\begin{array}{l}\text { Sierra centro y sur } \\
\text { Sierra norte }\end{array}$ & /kisa/ & 'ortiga' \\
\hline $\begin{array}{l}{[\text { cia }]} \\
{[\text { sia }]}\end{array}$ & /ciya/ & Sierra norte y centro & /č’iya/ & $\begin{array}{l}\text { 'liendre' } \\
\text { Sierra sur }\end{array}$ \\
\hline [čaway] & $\begin{array}{l}\text { /čaway/ } \\
\text { /kapina/ }\end{array}$ & $\begin{array}{l}\text { Sierra centro } \\
\text { Sierra norte y sur }\end{array}$ & /č’away/ & 'ordeñar' \\
\hline [čuža] & /ču入a/ & Sierra norte y centro & /ču’入a/ & 'único, impar' \\
\hline 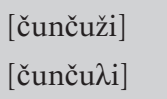 & $\begin{array}{l}\text { /čunču } \mathrm{i} / \\
\text { Sierra sur }\end{array}$ & Sierra norte y centro & /č’unčul/ & 'tripa' \\
\hline $\begin{array}{l}\text { [čukža }] \\
{[\check{c} u g \lambda a]}\end{array}$ & /čuk $\lambda \mathrm{a} /$ & $\begin{array}{l}\text { Sierra norte y centro } \\
\text { Sierra sur }\end{array}$ & /č'uk $\lambda \mathrm{a} /$ & 'choza' \\
\hline
\end{tabular}

Pero en la Sierra norte y centro se pueden encontrar, actualmente, unos pocos ejemplos de pares mínimos entre /č/ y / ф / en palabras de origen quichua. Este fenómeno seguramente se debe a la necesidad de mantener alguna distinción al no existir las aspiradas y glotalizadas como en el Cuzco.

\begin{tabular}{|lll|}
\hline /čanka/ & 'pierna' & \\
/ çanka/ & 'granos machucados' & \\
/čunkana/ & 'agrupar de diez en diez' & [čunkay] (Cuzco) \\
/ çunkana/ & 'chupar' & [č’onqay] (Cuzco) \\
\hline
\end{tabular}

En la Sierra sur, que no tiene / $\not /$ en el sustrato, para diferenciar /č/ y / ф/ este último ha evolucionado a [s]. Así, palabras que en la ma- 
yor parte del Ecuador se pronuncia con / $/$ / como: [pacak] <patsak> 'cien', en esta zona se pronuncia [pasak]. La palabra [micak] <mitsak $>$ 'tacaño' se realiza igualmente como [misak]. En esta última zona se ha dado una evolución ulterior de $|\phi|>/ s /$, por desafricación. Sin embargo, en algunos casos se realiza como [č] en Ecuador, incluida la Sierra sur, por ejemplo: [čug $\lambda \mathrm{a}$ ] /čuk $\lambda \mathrm{a} /$ 'choza', /čunču $\lambda \mathrm{i} /$ 'tripa', /ču $\lambda \mathrm{a} /$ 'único', / čuru/ 'caracol, espiral'. Algunos / $/$ / se correlacionan con /č'/ cuzqueño, pero otros provienen de sustratos prequichuas. Los elementos de sustrato más probables son fitónimos como /yuđu/ 'tipo de planta que crece junto a los ríos' en la Amazonía, /pucu/ 'tipo de hierba silvestre en la provincia de Cotopaxi', etc. Se ha detectado la presencia de un sustrato / $\not$ / en cinco de las seis zonas dialectales que presentarán en el capítulo $5 .{ }^{60}$ La única que no tiene es la Sierra sur.

\section{El uso del fonema /šl}

Como se verá en el capítulo 5, en cinco de las seis zonas dialectales del Ecuador se usa /š/. Esta es una de las diferencias con el ingano de Colombia, en donde este fonema se realiza como [s], de manera similar al cuzqueño. La única zona donde se ha producido este fenómeno es en la Amazonía norte del Ecuador, pero no de manera general en el léxico, como ocurre en el colombiano, sino solo en los morfemas \{-ška\} y \{-špa\}. Esta última característica la comparte con el napeño del Perú, según Mercier (1983).

\section{Nivel morfológico}

Según Parker (1969c/2013), las clases mayores de las raíces del protoquechua son los sustantivos, verbos, ambivalentes y también las

60 De las seis zonas dialectales, en la Sierra sur no se han encontrado sustratos con $\mid \not /$. Las palabras que en las otras cinco zonas se pronuncian con [£], aquí se pronuncian con $[\mathrm{s}]$. 
partículas. ${ }^{61}$ De ellos, los sustantivos son formas libres y flexionan con los morfemas de persona (posesora), ${ }^{62}$ número y caso. Los verbos son formas ligadas que flexionan de acuerdo a la persona, tiempo, aspecto, modo y subordinación. Los ambivalentes comparten rasgos con las categorías nominales y verbales. Las partículas, con excepción de los adverbios, ${ }^{63}$ no flexionan.

Luego de cotejar las diferentes hablas del quechua, Parker reconstruyó 36 morfemas derivadores, 18 flexivos entre verbales y nominales, y 5 enclíticos (independientes) para el protoquechua. Cabe anotar que en el caso de los flexivos verbales Parker tiene algunas vacilaciones, sin embargo, a pesar de estas limitaciones subyacentes a una tarea tan compleja como la de acometer una reconstrucción del protoquechua, la propuesta de Parker sigue siendo útil para continuar con las investigaciones en esta dirección.

Por otra parte, como lo han señalado varios investigadores, entre ellos Muysken (1981), en el quichua ecuatoriano existe una reducción importante en algunos de los sectores de la morfología en comparación con lo que ocurre en los dialectos actuales correspondientes al QI, QIIA y QIIC. La reducción se ha dado principalmente en los sistemas nominal y verbal, no tanto en el de los morfemas independientes. Además de la reducción morfémica, se constatan — como se va verá luego- procesos de resignificación y nuevos desarrollos morfológicos en los dialectos ecuatorianos.

\section{Sistema nominal}

Este sistema está constituido por los morfemas, tanto derivativos como flexivos, que se juntan al nombre.

61 Las partículas comprenden a los negadores, adverbios e interjecciones.

62 En el quichua ecuatoriano la flexión de persona se ha perdido, al parecer, a partir del siglo XVIII.

63 Un ejemplo de flexión del adverbio /achka/ es: /achkata munani/ 'quiero mucho'. 
1. Poco uso de los posesivos de persona. ${ }^{64}$ En cuanto a los morfemas nominales flexivos de persona debe señalarse que en el quichua ecuatoriano hay poco uso de los morfemas posesivos de persona. Para resolver esta situación se recurre al morfema genitivo $\{-\mathrm{pak} / \mathrm{pa}\}$, añadido al nombre o pronombre, que funciona como posesor, por ejemplo: <paypak wasi> 'su casa', < María-pak wasi> 'casa de María'. Además, en el caso de la primera persona, tanto singular como plural, se recurre a la simple yuxtaposición entre el posesor y el poseído. Así, se tiene $<$ ñuka wasi $>$ 'mi casa' y < ñukanchik wasi $>$ 'nuestra casa', en lugar de $<$ wasi-y, wasinchik $>$, respectivamente. Para destacar mejor la diferencia que existe en este punto entre el quichua ecuatoriano y los del Perú (representados por el QIIC), ${ }^{65}$ tenemos:

64 Ha sido común, entre los estudiosos de la morfosintaxis del quichua ecuatoriano, indicar que en el habla contemporánea no existen sufijos de persona que se juntan a los nombres para indicar posesión. Sin embargo, hay un estudioso que muestra su presencia no solamente en los textos de finales de siglos XIX y principios del siglo XX de autores como Grimm, Paris o Guzmán, sino que ha detectado su uso en el quichua oral actual de hablantes de algunas comunidades de Cotopaxi, Pichincha y Azuay (Garcés, 1997, pp. 99-100). Entre los ejemplos trae el siguiente: [turin šamukpi pai kontenta gaxun, turin ižakpi pai žaki gaxun] 'cuando viene su hermano, ella se pone contenta; cuando no está su hermano, ella está triste' (Juan José y Albino Iza, comunicación personal, marzo 1994). Aquí puede observarse la expresión $<$ turin $>$, en la cual el morfema $\{-n\}$ colocado a continuación de $<$ turi $>$, 'hermano de hermana', significaría 'su hermano', en lugar de la expresión genitivodativo < paypak turi shamukpi $>$ que es de esperarse. En este caso se constata que el morfema posesivo de la tercera persona del singular está presente en algunos contextos del habla actual. El autor de este estudio trae otros ejemplos con el posesivo de la segunda persona del singular. Además, subraya el caso de $<$ Apunchik $>$ 'nuestro Señor', que es la unión de $<$ Apu $>$ 'señor' y el morfema posesivo de la primera persona del plural inclusiva $\{$-nchik\}. De confirmar esto las investigaciones, sería plausible plantearse el rescate de esas marcas de persona en el quichua ecuatoriano.

65 Características de estos dialectos pueden consultarse en Cerrón-Palomino (1987, pp. 221-247). 


\section{0}

\begin{tabular}{|lll|}
\hline Variedades ecuatorianas & QIIC (cuzqueño) & Glosa \\
Ñuka-(pak) allku & allqu-y & 'mi perro' \\
Kan-pak allku & allqu-yki & 'tú perro' \\
Pay-pak allku & allqu-n & 'su perro' \\
Ñuka-nchik (pak) allku & allqu-yku & 'nuestro perro' (excl.) \\
Nuka-nchik (pak) allku & allqu-nchik & 'nuestro perro' (incl.) \\
Kankuna-pak allku & allqu-yki-chik & 'vuestro perro' \\
Paykuna-pak allku & allqu-nku & 'su perro' \\
Ñuka mikushka & miku-sqa-y & 'lo que he comido' \\
Kan mikushka & miku-sqa-yki & 'lo que has comido' \\
Pay mikushka & miku-sqa-n & 'lo que ha comido' \\
\hline
\end{tabular}

Esta característica diferencia al ecuatoriano inclusive de la mayor parte de hablas de la Amazonía peruana, aunque ellas también están en el grupo QIIB. Así, según Landerman (1973, pp. 105-106), el quechua del Pastaza peruano sí contiene las marcas personales de posesivo. Consecuentemente, la carencia de los morfemas de marcas posesivas personales solo ocurre en el quichua ecuatoriano, en el peruano de Loreto y en el ingano de Colombia.

2. La fusión de los morfemas de caso: posesivo $\{-p a\}$ y dativo $\{-p a k\} .{ }^{66}$ En las hablas del Ecuador, de Loreto (Perú) y en el ingano, no se hace distinción entre estos dos morfemas. Hubo, pues, una fusión entre ambos morfemas. Por ejemplo:

\begin{tabular}{|lll|}
\hline Ecuatoriano & Cuzqueño & Glosa \\
Mariapak wasi & Mariapa wasi & 'casa de María' \\
Mariapak wasi & Mariapak wasi & 'casa para María' \\
\hline
\end{tabular}

66 Actualmente, algunos quichuistas ecuatorianos están propugnando restablecer la diferencia a nivel escrito entre el posesivo y el dativo, lo cual deberá ser discutido para valorar su conveniencia. Aquí, esta posibilidad la señalamos como un hecho que tendrá algunas repercusiones en la estandarización de la escritura de la lengua. 


\section{1}

3. Ausencia del privativo \{-naq\}. En la nominalización denominativa, en las hablas ecuatorianas, no se usa el morfema privativo \{-naq\}, que de existir se hubiera realizado como [-nak], y que es el correlato del morfema $\{$-yuq\}, que en el ecuatoriano se realiza como [yuk]. La noción de privación se realiza con una circunlocución a base del verbo $<$ illa-y> 'faltar'. Así, lo que en dialectos del Perú sería <wasi-naq>, se corresponde con $<$ wasi illak $>$ en el Ecuador.

4. Uso de diminutivos $\{-k u,-w a,-l l a\}$ en lugar de $\{-c ̌ a\}$. En lugar del morfema diminutivo $\{-c ̌ a\}$, que está presente en varios dialectos del QIIC, en el Ecuador se usan los morfemas $\{-\mathrm{ku}\}$ en la Sierra norte, $\{-w a\}^{67}$ en la Sierra centro y $\{-\lambda \mathrm{a}\}$ en la Sierra sur. ${ }^{68}$ Por ejemplo:

\begin{tabular}{|lll|}
\hline /wasi/ & 'casa' & Todo el país \\
/wasi-ku/ & 'casita' & Sierra norte \\
/wasi-wa/ & 'casita' & Sierra centro y Amazonía \\
/wasi-lla/ & 'casita' & Sierra sur \\
\hline
\end{tabular}

El caso de $\{-\lambda \mathrm{a}\}$ se remonta al protoquechua y constituye un rasgo de preservación.

\section{Sistema verbal}

Este sistema está constituido por los morfemas derivativos y flexivos que se juntan al verbo. En el sistema verbal, particularmente en la verbalización deverbativa, es donde existe mayor reducción e innovación. Así, mientras que varios dialectos del QI y también del QIIC llegan a tener hasta 26 morfemas verbalizadores deverbativos, en el Ecuador solo se emplean siete, que son compartidos con los dialectos antes se-

67 Todo indica que $\{$-wa $\}$ proviene de $<$ wawa $>$ 'niño, niña, tierno', pues se puede también decir $<$ wasi wawa $>$ con el mismo sentido que $<$ wasiwa $>$.

68 En la Sierra sur, en muchas comunidades, se ha generalizado el uso del diminutivo del castellano en lugar del morfema quichua $\{-\lambda a\}$. Así, dicen /ñuka wasizitu/ en lugar de /ñuka wasìa/ 'mi casita'. Lo propio ocurre en los dialectos de Puno (Perú) y Bolivia. 
ñalados y que son: el desiderativo $\{$-naya- $\}$, el repetitivo $\{$-paya $\}$, el continuativo $\{$-raya- $\}$, el cislocativo $\{-\mathrm{mu}-\}$, el causativo $\{-c ̌ i\}$, el recíproco $\{$-naku-\} y el frecuentativo \{-ykača\}. Así pues, según Parker (1976, pp. 115-116) en las provincias de Huaraz, Pomabamba y Antonio Raimondi del dialecto Ankash-Huailas correspondientes al QI, hay 26 morfemas verbalizadores deverbativos. Según Cerrón-Palomino (1976, pp. 181215) en Junín-Huanca del QI hay también 26 verbalizadores deverbativos. En el dialecto cuzqueño, según la lista presentada por Cusihuaman (1976, pp. 193-2236) correspondiente al dialecto QIIC, se señalan más verbalizadores deverbativos que los anteriores del QI.

Aparte de esta situación de reducción del número de verbalizadores deverbativos y del surgimiento de algunos desarrollos propios, existen otras características del sistema morfológico verbal del quichua ecuatoriano que se verán a continuación.

1. Uso de $\{-n a\}$ como infinitivo verbal. En teoría, el infinitivo es un verbo no finito, es decir, se trata de una forma verbal sin tiempo, persona ni número, y ese sentido se parece más a un nombre. Sobre la marca de infinitivo en quechua ha existido una larga discusión. Domingo de Santo Tomás (1560/1995, p. 100) en el "Capítulo nono" no lo define con claridad. Se limita a poner ejemplos de su funcionamiento como nombre. Así, en su gramática trae la expresión "micui allí" traducida como 'comer es bueno', no es una expresión del habla diaria en el quichua ecuatoriano. Esa idea se expresaría con "micuica allimi (can)" 'el comer es bueno'. En este ejemplo y en los otros que señala el autor como infinitivo, la $<\mathrm{i}>$ aparece como marca de nominalización. Mientras que en el capítulo 5 dice lo siguiente sobre el modo infinitivo: "El presente se forma de la primera persona del presente de indicativo quitando la $n$, diciendo coyay" (1560/1995, p. 99). Sin embargo, como lo han sugerido algunos autores, especialmente Cerrón-Palomino en el estudio introductorio a la reedición de la gramática de Domingo de Santo Tomás ( $c f .1560 / 1995$, p. XXXVII), habría otras expresiones del autor de la primera gramática, de donde se podría intuir la marca más aproximada al infinitivo del verbo quichua. Así, en el capí- 
tulo 10 de la obra del dominico se encuentran expresiones como las siguientes: $<$ ñoca cuyangapac xamuni $>$ 'yo vengo a amar' $y<$ ñocanchic coyangapac, xamunchic > 'nosotros venimos a amar' (1560/1995, p. 103). En ellas, quitando la persona, se podría desglosar la forma infinitiva a partir de la expresión <kuya-nqa-ø-paq > 'a amar'. Eliminando \{-paq\}, quedaría $<$ kuyanqa $>$, y esta sería la forma del infinito verbal. En consecuencia, se podría postular como marca de infinitivo originaria el morfema $\{-n q a\}$.

Por otra parte, al menos desde fines del siglo XIX, a nivel escrito, en Ecuador se viene usando el morfema $\{$ na $\}$ como marca de infinitivo, mientras que en hablas de otros países se usa $\{-y\}$. La versión más antigua sobre esta cuestión en el ecuatoriano es el anónimo de 1753, atribuido al jesuita Nieto Polo. En ese texto se señala que el infinitivo es representado por la forma $\{$-nga\}, pues dice que el infinito de 'amar' es < cuianga $>$. Esto se puede observar en el siguiente texto: "Infinitivo. Amar. Cuianga. Efte infinitivo lo ufan los Indios muchas veces, como

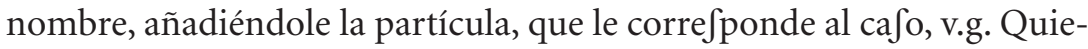
ro comer, Micungata munani” (Anónimo, 1753, folio 12).

Este dato atribuido a Nieto Polo es valioso, pues nos permite confirmar que la marca $\{-$ na $\}$ provendría de ${ }^{*}\{-$ nqa $\},{ }^{69}$ el cual se habría ido simplificando en $\{-$ na $\}$ hacia fines del siglo XVII y comienzos del XVIII.

Posteriormente, el padre Paris (1892/1924), Luis Cordero (1892/1989) y el padre Grimm (1896) emplean la forma infinitiva de los verbos con $\{-n a\}$. Así, 'amar' es <cuyana $>$. Actualmente, si se pregunta a un quichua-hablante bilingüe ¿cómo se dice sembrar?, generalmente responderá [tarpu-na] mas no [tarpu-y], pues este último se asocia más con el imperativo de segunda persona singular: 'siembra tú. Sin embargo,

69 Lo mismo puede decirse del origen del obligatorio $\{-$ na $\}$ que también proviene del $*\{$-nqa $\}$. Esto puede comprobarse con la frase de una canción quichua que se canta en Saraguro: <Ishkay wawa charinkarayku kanllawanmi kawsasha>, cuya interpretación sería: 'Por tener dos hijos solo contigo viviré'. 


\section{4}

cuando la pregunta es a la inversa: ¿Qué significa [tarpu-na]?, le contestan 'está de sembrar', pues se asocia con la forma de obligatoriedad $<$ tarpunami kan $>$. Hubiera sido interesante conocer cómo concebía el infinitivo el padre Lobato, indígena quichua-hablante de la comunidad de Cacha, actual provincia de Chimborazo, de quien se dice que escribió una gramática del quichua ecuatoriano antes de viajar a radicarse en el Perú en 1885.

Como se mencionó, a partir de las obras de fines del siglo XIX, con excepción del padre Guzmán (1920), se hizo costumbre representar en las gramáticas y diccionarios del quichua ecuatoriano el infinitivo con $\{-n a\}$. Así, se escribe < puñu-na, ka-na $>$ 'dormir, ser', respectivamente; mientras en el resto de países escriben $<$ puñu-y, ka-y $>.^{70} \mathrm{El}$ morfema $\{$-na\}, actualmente en Ecuador, en pocos casos se usa para la formación de nombres concretos. Por ejemplo:

\begin{tabular}{|ll|}
\hline miku-na & 'comida' \\
picha-na & 'escoba' \\
purik-na & 'caminata' (en la Amazonía se refiere al paseo familiar por varios días \\
& en la selva)
\end{tabular}

2. No distinción de plural inclusivo y exclusivo. El ecuatoriano no distingue entre el plural inclusivo y el plural exclusivo, tanto a nivel pronominal como verbal de la primera persona. Esta característica del ecuatoriano es compartida con el ingano de Colombia y el amazónico peruano. Por ejemplo:

\begin{tabular}{|lll|}
\hline Ecuatoriano & Peruano & Glosa \\
ñuka-nchik & ñuqa-yku/ñuqa-ykuna & 'nosotros' (exclusivo) \\
ñuka-nchik & ñuqa-nchik & 'nosotros' (inclusivo) \\
miku-nchik & mikuku-yku/miku-ykuna & 'comemos' (nosotros exclusivo) \\
miku-nchik & miku-nchik & 'comemos' (nosotros inclusivo) \\
\hline
\end{tabular}

70 Actualmente, algunos quichuistas indígenas de Ecuador proponen usar el morfema $\{-y\}$ como marca de infinitivo para unificarse con los otros países. Sin embargo, a la luz de estos datos, podría postularse que la marca de infinitivo en $\{$-na\} es un desarrollo ecuatoriano que puede mantenerse en la escritura unificada. 
3. Uso del factitivo $\{-c h i-\}$ en lugar de $\{-c h a-\}$. En lugar del protomorfema factitivo $\{-$ ča $\}$ se usa en todos los dialectos del Ecuador el morfema $\{$-či $\}$. Al parecer, esto implicaría la fusión del factitivo $\{-$ ča $\}$ con el causativo $\{$-či $\}$. Por ejemplo:

\begin{tabular}{|lll|}
\hline Ecuatoriano & Hablas de otros lugares & Glosa \\
wasichini & wasichani & 'hago casa' \\
pampachini & pampachani & 'aplano' \\
\hline
\end{tabular}

4. Uso del reflexivo $\{-r i-\}$ en lugar de $\{-k u\}$. Por ejemplo:

\begin{tabular}{|lll|}
\hline Ecuatoriano & Hablas de otros lugares & 'Glosa' \\
arma-ni & arma-ku-ni & 'baño' \\
arma-ri-ni & arma-ku-ni & 'me baño' \\
\hline
\end{tabular}

5. La no diferenciación de palabras terminadas en vocal o en consonante en el uso del morfema $\{-p a k /-p a\}$. En el QIIA y QIIC, después de vocal, estos morfemas se realizan como [p] y como [b], respectivamente. En tanto que después de consonante se pronunciaría [pa pak paq] fuera de Ecuador, incluido en el ingano de Colombia y el loretano del Perú. Este morfema se pronuncia de la siguiente manera dependiendo de si el nombre termina en vocal o en consonante:

\begin{tabular}{|ll|}
\hline [maria-p wasin $]$ & 'casa de María' \\
{$[$ kuntur-pa wasin $]$} & 'casa del Cóndor' \\
\hline
\end{tabular}

En el ecuatoriano no se aplica esta regla, pues se usa [pa pak] con algunas otras variaciones que constan en el capítulo 5, tanto después de vocal como de consonante. Por ejemplo:

\begin{tabular}{|lll|}
\hline $\begin{array}{l}\text { Maria-pak wasi } \\
\text { Kuntur-pak wasi }\end{array}$ & {$[$ mariapa wasi $\sim$ mariapak wasi $]$} & 'casa de María' \\
& 'casa del Cóndor' \\
\hline
\end{tabular}


Esto prueba que, en verdad, el protomorfema fue ${ }^{\star}\{-$ pa $\}$ y la alomorfía es propia de los dialectos que sincoparon la vocal. Sin embargo, se debe señalar que existen dialectos peruanos que mantienen $\{-\mathrm{pa}\}$ en ambos contextos.

6. Desarrollos morfológicos. Entre los morfemas de innovación que se han desarrollado en el quichua ecuatoriano están: el de cortesía $\{$-pa- $\}$; el durativo $\{$-ku- $\}$ en lugar de ${ }^{\star}\{$-yka $\}$; el reflexivo $\{$-ri $\}$ en lugar $\mathrm{de}^{*}\{-\mathrm{ku}-\}$ (estos dos últimos propuestos para el protoquechua por Parker, 1963-1972/2013, p. 84); el incoativo \{-kri\} en la Sierra; el inceptivo $\left\{\right.$-nka-raku\} en la Amazonía. ${ }^{71}$ Con lo cual los morfemas verbalizadores deverbativos alcanzan a 13. Por ejemplo:

\begin{tabular}{|ll|}
\hline miku-y & 'come' \\
miku-pay & 'come por favor' \\
tarpu-ni & 'siembro' \\
tarpu-ku-ni & 'estoy sembrando' \\
arma-ni & 'baño' \\
arma-ri-ni & 'me baño' \\
miku-ni & 'como' \\
miku-k-ri-ni' & 'voy a comer' \\
miku-ni & 'como' \\
miku-nka-ra-ku-ni & 'estoy yendo a empezar a comer' \\
\hline
\end{tabular}

71 El desarrollo $\{$-nka-ra-ku- $\}$ proviene del ${ }^{*}\{$-nqa $\}$ y de $\{$-ra-ku- $\}$. La explicación es similar a la del morfema $\{-\mathrm{k}-\mathrm{ri}\}$ que se señala más abajo. A esto hay que añadir el elemento lexical <kikin $>$ usado en la Sierra norte y centro con el significado de 'usted', el cual se usa para dirigirse a personas mayores o desconocidas.

72 Sobre $\{$-kri- $\}$ se discute con respecto a la forma de escribir, pues algunos plantean escribir $<$ mikuk rini>, debido a que ese sería el origen de la expresión; sin embargo, otros creen que hay que tomar en consideración que en la mente de los hablantes la secuencia ya se habría internalizado como una unidad. 
Se puede postular que el desarrollo $\{-\mathrm{kri}-\}$ proviene del agentivo $\{-\mathrm{k}\}$ y de $\{$ ri- $\}$ del verbo ir. Igualmente el desarrollo $\{-n k a-r a k u-\}$ provendría de $\{-\mathrm{nka}\}$, de $\{-\mathrm{ra}-\}, \mathrm{y}\{$ rura-y $\}$ 'hacer', y del continuativo $\{-\mathrm{ku}-\}$.

\section{Sufijos independientes}

Los sufijos independientes se juntan tanto al nombre como al verbo. Además, ellos indican si la oración es afirmativa, interrogativa, negativa, etc.

En este sistema de sufijos hay desarrollos como: $\{$-chari $\},\{$-mari $\}$, $\{$-yari $\}$, aunque se conoce que esto no es privativo del quichua ecuatoriano. Se puede postular que estas secuencias son el resultado de ${ }^{\star}\{$ chu-ari $\}$, ${ }^{*}\{$-mi-ari $\}$ y ${ }^{*}\{$-ya-ari $\}$, respectivamente. Los morfemas independientes $\{$-chari\}, \{-mari\} ya se encuentran registrados en el Anónimo de 1753.

Estas construcciones al parecer son bimorfémicas, sobre la base de /ari/, expresión afirmativa. De los morfemas independientes del protoquechua, señalados por Parker, en el ecuatoriano, no se usa $\{-\tilde{n} a\}$. En cuanto a los reportativos, el único usado es en Ecuador $\{-s ̌ i\}$.

\section{Nivel morfosintáctico}

En este nivel no hay muchas diferencias con los otros dialectos, sin embargo, se puede notar el surgimiento de casos de reducción y ensamblaje, en el sentido señalado por Cerrón-Palomino (1997). Uno de ellos es el que se ha dado en la Amazonía sur, en el río Bobonaza (prov. de Pastaza): los hablantes de las comunidades de Sarayacu, Pacayacu, y Teresa Mama suelen ensamblar la palabra que termina en el morfema afirmativo $\{-\mathrm{mi}\}$ con el verbo $\{\mathrm{ka}-\}$, el cual ha sufrido un proceso de reducción y de su forma se ha suprimido /k/, así:

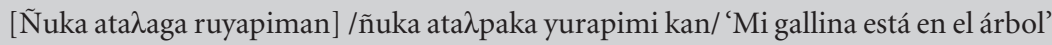


178

\section{Rasgos conservadores del quichua ecuatoriano}

Los morfemas independientes: validador $\{-\mathrm{mi}\}$, interrogativo

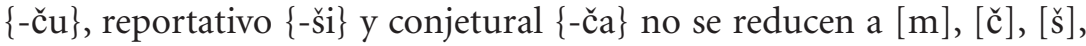
[ᄃ̌], respectivamente, cuando se juntan a palabras que termina en vocal. Así por ejemplo, en el quichua ecuatoriano el sufijo $\{-\mathrm{mi}\}$ se realiza como [mi], tanto después de consonante como después de vocal. No existe la diferenciación como en otros dialectos en los cuales, cuando la palabra a la que se añade termina en consonante, se realiza como [mi] y como $[\mathrm{m}]$ cuando aquella termina en vocal. En este caso, la forma ecuatoriana resulta ser conservadora. Por ejemplo:

\begin{tabular}{|lll|}
\hline Forma ecuatoriana & QIIA-QIIC & Glosa \\
Payka alli yayami kan & Payqa alli yayam kan & 'Él es un buen papá' \\
Payka yachachikmi kan & Payqa yachachikmi kan & 'Él es profesor' \\
Misimi chayta mikurka & Misim chayta mikurqa & 'El gato comió eso' \\
Kunturmi chayta mikurka & Kunturmi chayta mikurqa & 'El cóndor comió eso' \\
\hline
\end{tabular}

El mantenimiento, en todos los contextos, de la vocal en los morfemas posesivo-benefactivo $\{$-pak $\}$, afirmativo $\{-\mathrm{mi}\}$, reportativo $\{$-ši $\}$ y conjeturativo $\{$-ča $\}$ se puede considerar como un signo de conservacionismo frente a las hablas en las cuales, cuando la raíz a la que se adhieren termina en vocal, evolucionaron a formas con caída de la vocal de estos morfemas, dando lugar a las formas [p, m, š, č ], respectivamente, como ocurre en variedades del Perú.

\section{¿El ecuatoriano es una especie de koiné?}

Algunos lingüistas como Muysken, al analizar el léxico y también algunas estructuras del quichua ecuatoriano, llegan a sostener que el quichua ecuatoriano sería una koiné. Muysken argumenta sobre esta posibilidad de la siguiente manera: 
Koines $[s i c]$ se caracterizan lingüísticamente por una reducción morfológica y una nivelación o uniformización dialectal, y socio-históricamente por su origen en la expansión rápida de la lengua madre. Expansión rápida conduce a bilingüismo extenso y a un aprendizaje incompleto por hablantes de otras lenguas (1981, p. 18).

Esta hipótesis tendría cierta plausibilidad debido a los datos de documentos coloniales en los que se apoyan algunos autores para postular que el quichua fue introducido al Ecuador, fundamentalmente por los incas, en distintos momentos y con mitimaes de diferentes lugares del Perú. ${ }^{73}$ Además, en el léxico del quichua ecuatoriano existen términos provenientes tanto del QI como de las variedades del QIIA y QIIC. ${ }^{74}$

Muysken (1981, p. 7), al comparar los morfología del ecuatoriano con el cuzqueño, encuentra que hay coincidencia en varios morfemas: acusativo $\{$-ta $\}$; dativo direccional $\{$-man $\}$; ablativo $\{$-manta $\}$; locativo $\{$-pi\}, 'con' $\{$-wan $\}$, 'entre' $\{$-pura $\}$, 'a causa de' $\{$-rayku\}, 'hasta' $\{$-kama $\}$. Varios de estos son diferentes en el QI. Esta situación apoyaría el argumento de que el quichua ecuatoriano, a pesar de la distancia geográfica que separa a estas dos hablas, comparte con ellos nuestras similitudes.

73 Según Espinoza Soriano (1988), junto con las tropas de Túpac Yupanqui y de Huaina Cápac, vino un gran contingente de mitimaes del pueblo huayacuntu (Cajamarca, norte del Perú). Según este autor, Huaina Cápac dispuso que Carguatanta quedara al frente de los huayacuntu en Quito y luego que fue asesinado por los españoles, un descendiente suyo llamado Caxamarca llegó a ser curaca de los huayacuntu en Quito; este fue bautizado como Diego de Figueroa Caxamarca, aprendió a leer y escribir, a cantar y tañer instrumentos musicales, por lo cual fue escogido para ser preceptor en el colegio de naturales de San Andrés, en Quito. Al igual que este caso, seguramente hubo más mitimaes provenientes de otros lugares del Tahuantinsuyo que debieron haber influido en la conformación de las hablas del quichua ecuatoriano.

74 En el ecuatoriano no existe el fonema / $\hat{c} /$, sin embargo, en varias comunidades de la Sierra centro y norte existe la forma [kaĉa] 'costra', que según Parker (19631972/2013) se registra en Huailas QI y que sería parte del protoquechua. En otras comunidades, en cambio, dicen [karača], que provendría de [ ${ }^{*}$ qara-ča]. 
180

Sin embargo, Muysken no cree que el ecuatoriano esté directamente relacionado con el cusqueño:

Mi conclusión principal va a ser que el quechua ecuatoriano no tiene relación directa con el quechua cuzqueño o incaico, sino más bien ha pasado por un proceso de koinenización a base de variedades chinchay, la lengua general, además de tener influencia superestratal del quechua cuzqueño (1981, p. 1).

Según la hipótesis de Muysken, el quichua ecuatoriano estaría relacionado con el quechua sureño, a partir del cual el cuzqueño, tal como se lo conoce actualmente, se desarrolló con posterioridad a la llegada de los incas al Ecuador. Por esta razón no se puede considerar que el ecuatoriano sea "hijo" del cuzqueño. Una prueba de la relación del ecuatoriano con el sureño se puede observar en los siguientes morfemas:

\begin{tabular}{|c|c|c|c|c|}
\hline Morfema & QI & Sureño & Ecuador & \\
\hline Locativo & & $\{-\hat{c} a w\}$ & $\{-\mathrm{pi}\}$ & $\{-\mathrm{pi}\}$ \\
\hline Ablativo & & $\{$-piqta $\}$ & $\{$-manta $\}$ & $\{$-manta $\}$ \\
\hline Comparativo & $\{$-naw $\}$ & $\{$-hina $\}$ & $\{$-šina $\}$ & \\
\hline $1^{\circ}$ persona verbal presente & $\{-:\}$ & $\{-\mathrm{ni}\}$ & $\{-\mathrm{ni}\}$ & \\
\hline $2^{\circ}$ persona verbal pasado & $\{$-rqa-yki\} & $\{$-rqa-nki $\}$ & $\{-r k a-n k i\}$ & \\
\hline $1^{\circ}$ persona objeto & $\{-\mathrm{ma}\}$ & $\{-$ wa $\}$ & $\{w a\}$ & \\
\hline
\end{tabular}

Por el contrario, en cuanto al léxico — como se señaló en el capítulo 1, al tratar sobre las hipótesis del origen del quechua- se mencionó que existen algunos términos en los que el ecuatoriano coincide con el QI, mas no con el del Cuzco. Por ejemplo:

\begin{tabular}{|llll|}
\hline Léxico & QI & Cuzco & Ecuador \\
Agua & yaku & unu & yaku \\
Lluvia & tamya & para & tamya \\
Cuatro & chusku/trusku & tawa & chusku \\
Flor & wayta/sisa & t'ika & sisa \\
\hline
\end{tabular}


181

La discordancia entre las formas gramaticales y el léxico justificaría la idea de que el ecuatoriano es una especie de koiné. Sin embargo, para extraer conclusiones más plausibles tendrían que realizarse comparaciones con más ejemplos. Por el momento proponemos la ubicación de las hablas del quichua ecuatoriano al interior del grupo QIIB con la siguiente arborización del mismo: ${ }^{75}$

Figura 6

Ubicación del quichua ecuatoriano al interior de la rama QIIB

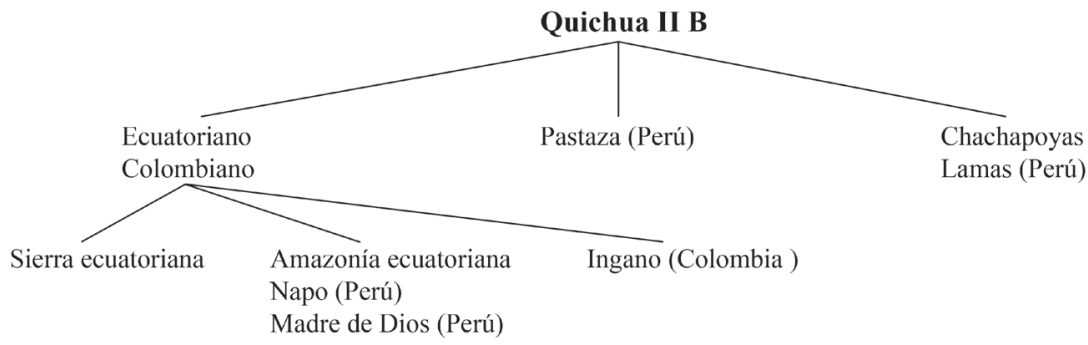

Fuente: el autor

Así, con los datos de Taylor $(1979,2000)$, se puede concluir que Chachapoyas se diferencia del resto por mantener la oposición č/ĉ, mientras el resto de hablas del QIIB no la mantiene. El habla del Pastaza $^{76}$ peruano se caracteriza, según Landerman (1973), por mantener, junto con los anteriores, las marcas posesivas. Ni las hablas ecuatorianas, ni el ingano de Colombia, como tampoco el napeño peruano, mantienen estas características. El ingano de Colombia ha fusionado los fonemas /š/ y /s/ en todos los contextos, según Tandioy (et al., 1978); en tanto que las hablas ecuatorianas y la napeña del Perú, mantienen la diferencia de esos fonemas en el léxico, excepto en los morfemas $\{$-špa $\}$

75 La variedad chincha de la costa centro-sureña del Perú, extinguida a fines del siglo XVI, también formaría parte del grupo QIIB.

76 No se ha conseguido información las características del quichua del río Tigre en el Perú, por lo cual no se lo ha incluido en el diagrama. 
182

y \{-ška\}, según se puede apreciar en Mercier $(1979,1983)$. Así pues, las hablas del Ecuador y el napeño peruano forman un conjunto dialectal. A este grupo habría que añadir, según Mercier (1983, p. 29), el habla de Madre de Dios, en el Perú, pues sus hablantes habrían sido llevados a ese lugar por los caucheros del poblado de Santa Rosa, que se hallaba ubicado en el Napo ecuatoriano. Este hecho habría ocurrido entre fines del siglo XIX y comienzos del XX.

La proximidad de las hablas ecuatorianas amazónicas con las del Napo-Perú y Pastaza-Perú, que se encuentran en el departamento de Loreto, puede deberse a la presencia por doscientos años de las misiones jesuitas de Maynas. Esta realidad se halla representada en un mapa de las misiones jesuíticas de Maynas elaborado por un misionero capuchino, Cabodevilla (1994, 104/2015, p. 146).

Figura 7

Mapa de las misiones jesuitas de Maynas

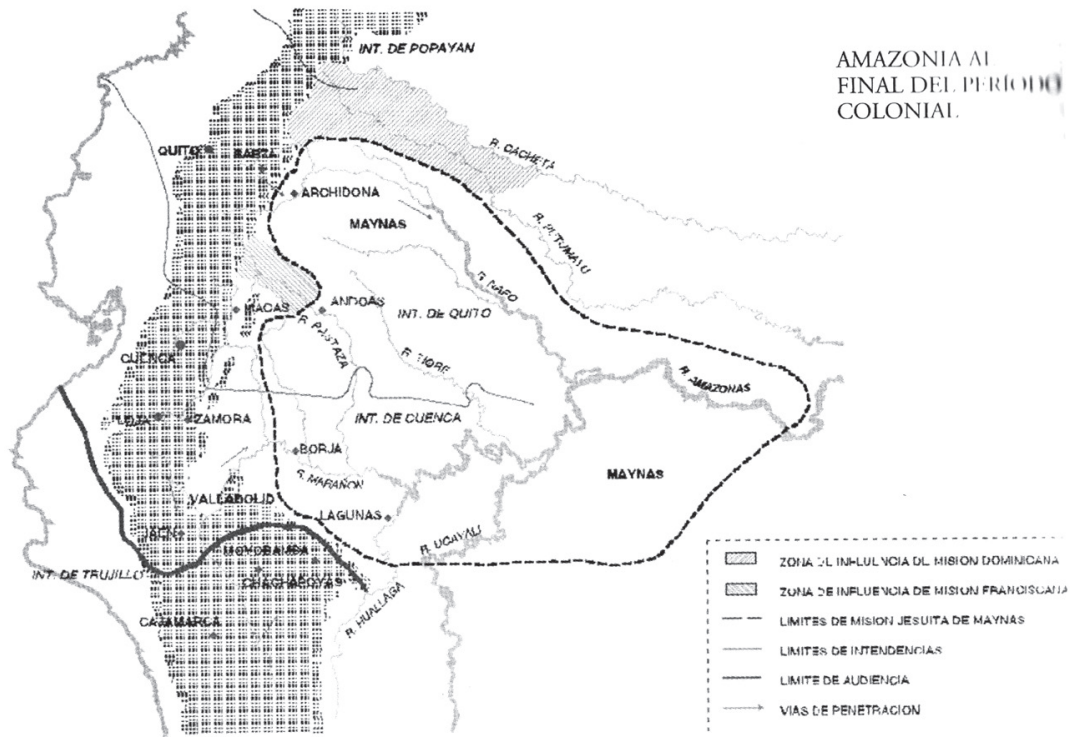

Fuente: Cabodevilla, 1995 
Seguramente por esta razón, en la primera página dedicada "Al lector" de la gramática de 1753, atribuida a Nieto Polo, denominada Breve instrucción o arte para entender la lengua común de los indios según se habla en la provincia de Quito, el autor subrayó lo siguiente:

Me dediqué a componer este Arte de la Lengua comun de los Indios de estas parte de Quito, y Maynas, para cuya composición me informe primero de alguno otro, que avia estado en Maynas, de cosas particulares, y dignas de apuntarse, para los que desean ir por alla, llevados de su zelo y fervor.

Vale anotar que los jesuitas misionaron Maynas desde comienzos del siglo XVII hasta su expulsión en 1767, por parte del rey Carlos III.

De las investigaciones de los autores mencionados se infiere que el ecuatoriano no está muy relacionado con las hablas de la Sierra central peruana (QI), a las cuales, a partir de fines del siglo XVI, las llamaron arbitrariamente chinchaisuyo. Tampoco está directamente relacionado con el cuzqueño actual. El quichua ecuatoriano estaría más relacionado con la variedad extinguida de Chincha, de la costa centro-sureña del Perú, descrita por el dominico Domingo de Santo Tomás. 